Research Article

\title{
Control of the Variable-Speed Pumped Storage Unit-Wind Integrated System
}

\author{
Yifeng Shi, ${ }^{1}$ Xiangjian Shi $\left(\mathbb{D},{ }^{1}\right.$ Chuanbao Yi, $^{2}$ Xufeng Song, ${ }^{2}$ and Xiaogang Chen ${ }^{3}$ \\ ${ }^{1}$ NR Electric Co., Ltd., Nanjing 211102, China \\ ${ }^{2}$ State Grid Xinyuan Company Ltd., Beijing 100761, China \\ ${ }^{3}$ State Grid Zhejiang Electric Power Co., Ltd., Zhejiang 310007, China
}

Correspondence should be addressed to Xiangjian Shi; shixj@nrec.com

Received 12 August 2019; Revised 18 December 2019; Accepted 2 March 2020; Published 29 March 2020

Academic Editor: Vincenzo Bianco

Copyright (@) 2020 Yifeng Shi et al. This is an open access article distributed under the Creative Commons Attribution License, which permits unrestricted use, distribution, and reproduction in any medium, provided the original work is properly cited.

The integration of variable-speed pumped storage unit (VS-PSU) guarantees an efficient peak regulation and frequency modulation of the power grid. The present research analyzes the active power flow of the VS-PSU under synchronous, subsynchronous, and supersynchronous speed in both generation and pumping modes. The control strategy of the VS-PSU is realized by the $d q$-axis vector control method. Furthermore, the control of the VS-PSU integrated with wind power has been conducted using DIgSILENT platform with the VS-PSU of $300 \mathrm{~kW}$ capacity. Results show that the fluctuation of the power output of the wind power plant can be reduced effectively. The safe, economical, and stable operation of power system integrated with wind power can be achieved by the significant contribution of the VS-PSU.

\section{Introduction}

The intensified integration of intermittent renewable energy sources such as wind, tidal, and solar power puts higher demands to the grid frequency control [1-3]. The refined frequency control approach is urgently desired in power network operation [3]. The pumped hydro storage (PHS) is known as the most reliable way for realization of peak load regulation, frequency modulation, and phase modulation, emergency reserve [4-9]. The traditional power generatormotor operates in the constant speed and frequency mode so that the pump-turbine operating condition is determined by the water head and load. The lack of power regulating the ability of the traditional constant-speed pumped storage units under pumping mode causes a significant impact on the absorption level of new energy in the regional power grid [10]. The variable-speed pumped storage unit (VS-PSU) responds faster under generation mode and adjusts the grid power under pumping mode more flexibly $[10,11]$. For PHS, the development of variable-speed operation was firstly reported in Japan in the 1990s [12], and results showed that the transient response characteristics were quite satisfactory.
Up to now, Japan and Europe possess the largest installed capacity of VS-PSU plants in the world [13] and have carried out in-depth work in the research and application of VSPSU [14-16], while in China, the growing tendency for the development of the PHS [17] indicates the tremendous potential to integrate the variable-speed technology in the near future.

PHS has the ability of spatial-temporal translation of energy. As an auxiliary peak-regulating power source for traditional power units, variable-speed pumped storage power station is of great significance to relieve the peakregulating pressure of power grid [18]. The active power is controlled by adjusting the rotor speed especially during the pumping mode [19-21]. A doubly fed induction machinebased variable-speed pumped storage (VSPS) system was established to investigate the performances in generating mode based on a comparison of phasor model and detailed model simulations [22]. The reactive/active power responses in a very short time for voltage and frequency control enables more dynamic tracking of the load variation because the power of the pump-turbine is proportional to the third power of the unit speed $[21,23,24]$. The variable-speed 
pumped storage power generator can operate within a certain speed range according to the change of water head to meet the optimal unit speed. Thus, cavitation and sediment wear of turbine blades can be reduced and the pump-turbine adapts to a wider head variation $[18,25,26]$. Despite all the advantages in installation of the VS-PSU, the economic and efficiency analysis is significant for practical industrial application. The economic benefits of converting an existing fixed-speed pumped storage hydropower plant to adjustable speed were estimated and they concluded that the final revenue is increased by 58\% [27]. Filipe et al. [28] presented an architecture of the optimized bidding strategy for VSPSU participated power plant.

Despite the various researches on the VS-PSU, there are still some problems to be solved in the aspects of participation of VS-PSU in the grid security and stability control strategy, economic dispatch, and the coordination control strategy with new energy. The present research analyzes power flow of the VS-PSU under both generation and pumping modes to provide the principle of VS-PSU integration. The mathematical models of the VS-PSU have been derived for the realization of doubly fed induction machine (DFIM) power control. Studies on the coordinated operation of the VS-PSU and wind power have been conducted by a systematic simulation. Two schemes are proposed to demonstrate the coordinated dispatch between VS-PSU and wind power.

\section{Operation Principle of the Variable-Speed Pumped Storage Unit (VS-PSU)}

2.1. Active Power Flow for the VS-PSU. The PHS power station operates under two main operating conditions: pumping and generation mode, which are used to regulate the peak and trough periods of power consumption, respectively. The stator of the doubly fed induction machine (DFIM) is connected to the grid, and the rotor adopts the three-phase symmetrical excitation winding. The excitation is provided by the frequency inverter with arbitrary adjustable amplitude, frequency, phase, and phase sequence. When the rotor windings of DFIM are fed with symmetrical alternating current, the rotation of the magnetic field relative to the rotor will be generated in the air gap with a speed of Nr. The relationship between the speed and the current frequency of the inverter is as follows:

$$
N_{r}=\frac{60 f_{2}}{p} \text {, }
$$

in which $N_{r}, f_{2}$, and $p$ represent the rotation speed of the magnetic field relative to rotor, the current frequency of the rotor, and the pole number of DFIM, respectively.

In order to achieve stable electromechanical energy conversion, the rotating magnetic fields of the stator and rotor must remain relatively static.

$$
N_{1}+N_{r}=N_{2}
$$

in which $N_{1}$ and $N_{2}$ represent rotor mechanical speed and the rotation speed of the magnetic field relative to stator. The positive or negative $N_{r}$ depends on the direction of $N_{1}$. When $N_{1}$ changes, $N_{r}$ is controlled by adjusting the rotor current frequency to maintain the speed balance. According to the variation of the rotor speed, the operation conditions of the DFIM can further be divided into three modes, namely synchronous, subsynchronous, and supersynchronous operation mode. In the synchronous operation mode, the unit outputs active power to the grid and the inverter provides DC excitation to the rotor winding under generation, whereas the grid feeds active power to the unit and the inverter provides DC excitation to the rotor winding under pumping mode. The active power flow during subsynchronous and supersynchronous operation is given in Figures 1 and 2 . In the subsynchronous operation mode, the unit outputs active power to the grid, and the grid feeds to the rotor winding through the inverter under the power generation condition (see Figure 1(a)), whereas the grid feeds active power to the unit, and the rotor winding outputs active power to the grid through the inverter under the pumping condition (see Figure 1(b)), while, in supersynchronous operation mode, the unit outputs active power to the power grid, and the rotor winding feeds it to the grid through the converter under the power generation condition (see Figure 2(a)), whereas the power grid feeds it to the generator, and the grid feeds active power to the rotor winding through the converter under the pumping condition (see Figure 2(b)).

The VS-PSU is excited through tailoring the current (or voltage) of slip frequency in the rotor of the DFIM. The constant frequency and constant voltage output of the stator are realized by adjusting the amplitude, frequency, and phase of excitation voltage. The rotor of the VS-PSU is excited by two "back-to-back" voltage-mode PWM converters which play a significant role in the electrical control system. The two-way flow of energy can thus be ensured with the rotor excitation frequency converter. Additionally, the voltage frequency, active power (generator-motor speed), and reactive power of the stator can be controlled by the realization of continuous adjustment of the amplitude, frequency, and phase of the output current. The output frequency range will meet the requirements of the DFIM including the speed regulation in a range of $90 \%$ to $110 \%$ synchronous speed and slip frequency adjustment in a range of $\pm 10 \%$ synchronous speed.

2.2. Control Strategy of VS-PSU. The target control object of the two PWM converters is a DFIM. Because of the magnetic coupling in the circuit of the DFIM, the mathematical model of the DFIM in the three-phase coordinate system is nonlinear and time-varying high order system. The general control diagram of the DFIM is designed in Figure 3, and detailed process has been provided in the following.

The $d q$-axis vector control technology is adopted to achieve decoupling control. The basic principle is to decompose three-phase current of the stator into DC excitation current component and torque current component by $d-q$ 


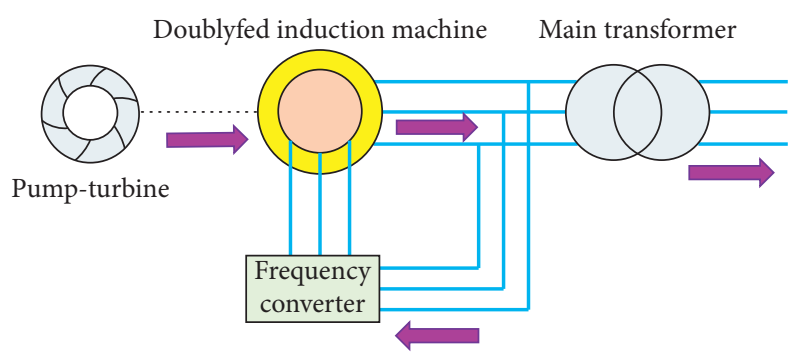

(a)

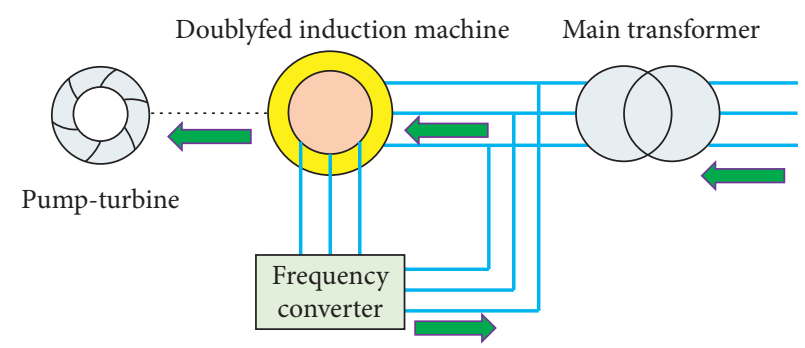

(b)

FIgURE 1: Active power flow of VS-PSU under subsynchronous operation: (a) generation mode; (b) pumping mode.

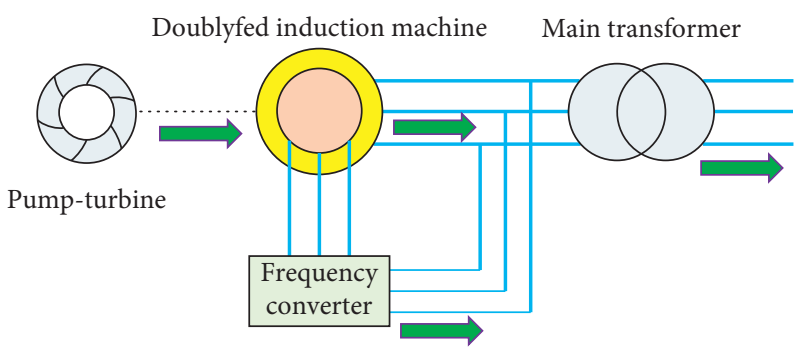

(a)

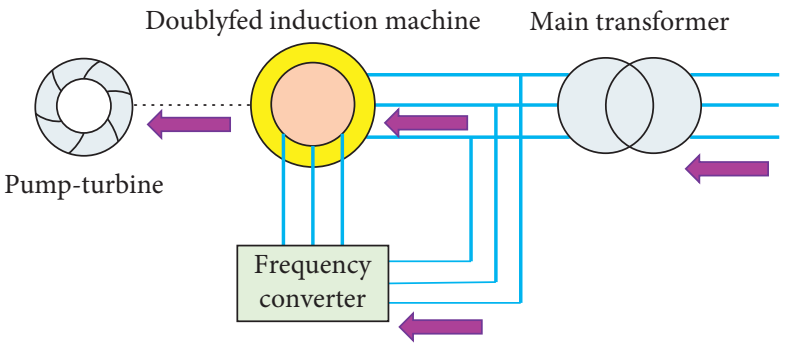

(b)

FIgURE 2: Active power flow of VS-PSU under supersynchronous operation: (a) generation mode; (b) pumping mode.

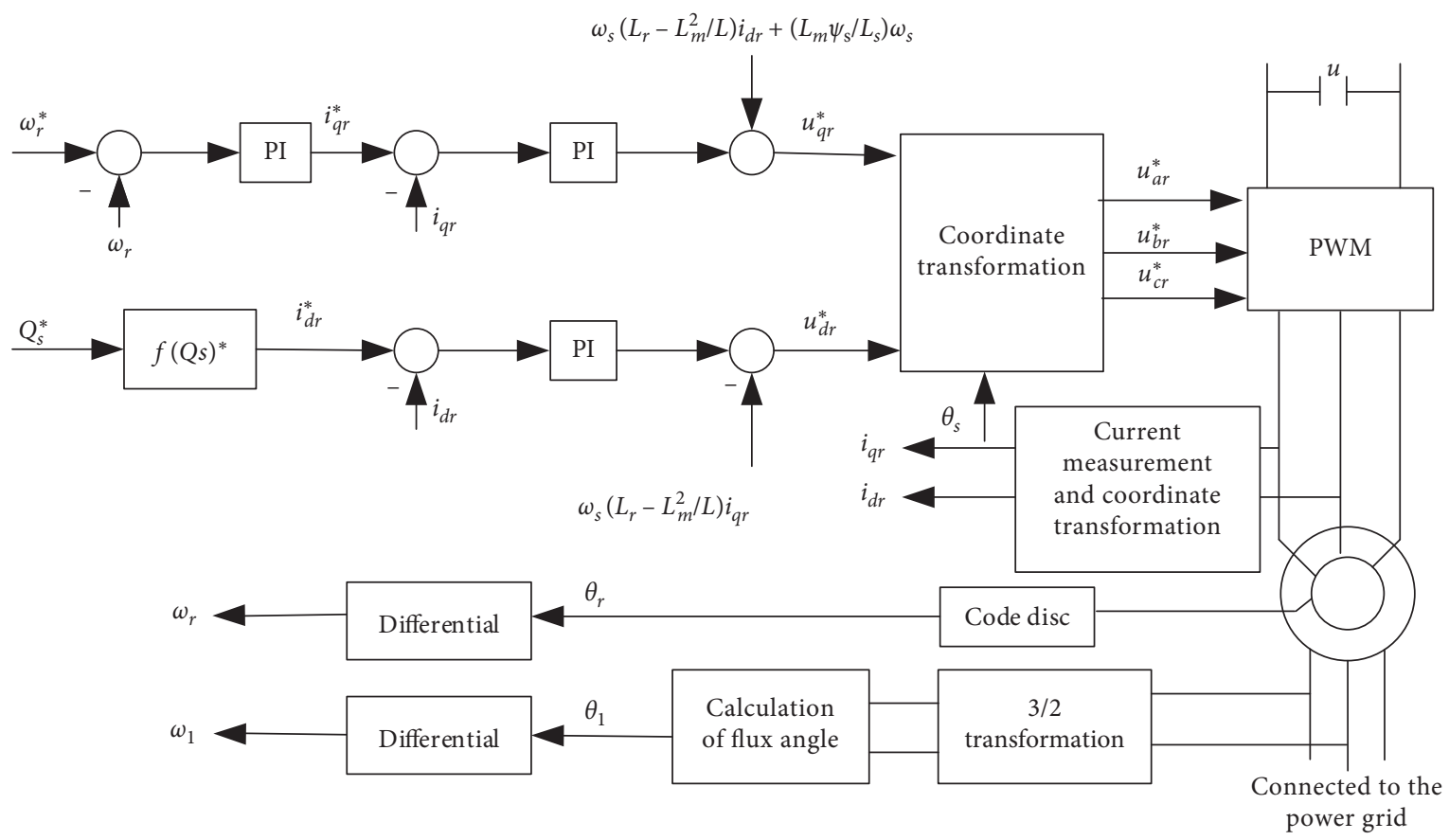

FIGURE 3: Control diagram of variable-speed constant-frequency DFIM.

rotation coordinate transformation. In the process of speed regulation, the excitation current component remains unchanged. At this time, the torque control law of dc motor can be simulated, and the electromagnetic torque moment can be controlled by adjusting the torque current component. Let the $d$ - $q$ axis rotate at the synchronous rotation speed, and the motor voltage and flux linkage equation of both the rotor and stator can be obtained as follows: 


$$
\begin{aligned}
& \left\{\begin{array}{l}
u_{d s}=R_{s} i_{d s}+p \psi_{d s}-\omega_{1} \psi_{q s}, \\
u_{q s}=R_{s} i_{q s}+p \psi_{q s}+\omega_{1} \psi_{d s}, \\
u_{d r}=R_{r} i_{d r}+p \psi_{d r}-\omega_{s} \psi_{q r}, \\
u_{q r}=R_{r} i_{q r}+p \psi_{q r}+\omega_{s} \psi_{d r},
\end{array}\right. \\
& \left\{\begin{array}{l}
\psi_{d s}=L_{s} i_{d s}+L_{m} i_{d r}, \\
\psi_{q s}=L_{s} i_{q s}+L_{m} i_{q r}, \\
\psi_{d r}=L_{r} i_{d r}+L_{m} i_{d s}, \\
\psi_{q r}=L_{r} i_{q r}+L_{m} i_{q s} .
\end{array}\right.
\end{aligned}
$$

The variables referred above (and below) have been summarized in Nomenclature section (presented at the beginning of the paper), while full voltage equation can be derived as follows:

$$
\left[\begin{array}{l}
u_{d s} \\
u_{q s} \\
u_{d r} \\
u_{q r}
\end{array}\right]=\left[\begin{array}{cccc}
R_{s}+L_{s} p & -\omega_{1} L_{s} & L_{m} p & -\omega_{1} L_{m} \\
\omega_{1} L_{s} & R_{s}+L_{s} p & \omega_{1} L_{m} & L_{m} p \\
L_{m} p & -\omega_{s} L_{m} & R_{r}+L_{r} p & -\omega_{s} L_{r} \\
\omega_{s} L_{m} & L_{m} p & \omega_{s} L_{r} & R_{r}+L_{r} p
\end{array}\right]\left[\begin{array}{c}
i_{d s} \\
i_{q s} \\
i_{d r} \\
i_{q r}
\end{array}\right] .
$$

The torque and motion equations is as follows:

$$
\begin{aligned}
T_{e} & =n_{p} L_{m}\left(i_{q s} i_{d r}-i_{d s} i_{q r}\right), \\
T_{e}-T_{l} & =\frac{J}{n_{p}} \frac{\mathrm{d} \omega}{\mathrm{d} t} .
\end{aligned}
$$

Generally, the vector control system of the asynchronous motor takes rotor flux as a reference, and then the direction of rotor flux is determined as $d$ axis of the synchronous coordinate system. However, if the doubly fed system with variable-speed and constant frequency is still oriented by rotor flux or air gap flux, the calculation of stator active power and reactive power will be complex, which will affect the real-time processing of the control system. Therefore, when the stator flux is oriented on axis $d$, the following equations can be obtained:

$$
\begin{aligned}
& \psi_{d s}=\psi_{s}=L_{s} i_{d s}+L_{m} i_{d r} \Rightarrow i_{d s}=\frac{\psi_{s}-L_{m} i_{d r}}{L_{s}}, \\
& \psi_{q s}=0=L_{s} i_{q s}+L_{m} i_{q r} \Rightarrow i_{q s}=-\frac{L_{m}}{L_{s}} i_{q r} .
\end{aligned}
$$

Since the stator side of the DFIM always runs at a fixed frequency, $50 \mathrm{~Hz}$ is considered for this research. In this case, the voltage drop of stator resistance is much smaller than the inverse potential of the motor. Therefore, the stator winding resistance of the motor can usually be ignored, and the stator voltage equation can be simplified as

$$
\left\{\begin{array}{l}
u_{d s}=0 \\
u_{q s}=\omega_{1} \psi_{d s}=U_{s}, \\
u_{d r}=R_{r} i_{d r}+\left(L_{r}-\frac{L_{m}^{2}}{L_{s}}\right) \frac{\mathrm{d} i_{d r}}{\mathrm{~d} t}-\left(L_{r}-\frac{L_{m}^{2}}{L_{s}}\right) \omega_{s} i_{q r}, \\
u_{q r}=R_{r} i_{q r}+\left(L_{r}-\frac{L_{m}^{2}}{L_{s}}\right) \frac{\mathrm{d} i_{q r}}{\mathrm{~d} t}+\left(L_{r}-\frac{L_{m}^{2}}{L_{s}}\right) \omega_{s} i_{d r}+\frac{L_{m} \psi_{s}}{L_{s}} \omega_{s} .
\end{array}\right.
$$

Corresponding torque equation is

$$
T_{e}=-\frac{n_{p} L_{m}}{L_{s}} \psi_{s} i_{q r}
$$

The active and reactive power of the rotor side can be obtained as

$$
\begin{aligned}
& P_{s}=T_{e} \omega_{1}=-n_{p} \frac{L_{m} \psi_{s}}{L_{s}} \omega_{1} i_{q r} \\
& Q_{s}=n_{p} \omega_{1} \psi_{d s} \frac{\psi_{d s}-L_{m} i_{d r}}{L_{s}} .
\end{aligned}
$$

It can be derived from equations (9) and (10) that the active power and reactive power of the generator stator have a linear relationship with the torque component and excitation component of the rotor current, respectively. The active power and reactive power of stator can be independently controlled by adjusting the two current components, and, thus, the power decoupling control is realized in the stator side.

Similarly, the rotor voltage equation can be obtained:

$$
u_{d r}=R_{r} i_{d r}+\left(L_{r}-\frac{L_{m}^{2}}{L_{s}}\right) \frac{\mathrm{d} i_{d r}}{\mathrm{~d} t}-\left(L_{r}-\frac{L_{m}^{2}}{L_{s}}\right) \omega_{s} i_{q r} .
$$

Let

$$
u_{d r}^{\prime}=R_{r} i_{d r}+\left(L_{r}-\frac{L_{m}^{2}}{L_{s}}\right) \frac{\mathrm{d} i_{d r}}{\mathrm{~d} t}
$$

and we can obtain

$$
\frac{u_{d r}^{\prime}(s)}{i_{d r}(s)}=R_{r}+\left(L_{r}-\frac{L_{m}^{2}}{L_{s}}\right) s
$$

where the transfer functions of $u_{d r}^{\prime}$ and $i_{d r}$ are linear. As can be seen from Figure 4 , we can obtain $u_{d r}^{\prime}$ from $i_{d r}$ after the PI regulation. $u_{d r}^{*}$ can be calculated by the full compensation of voltage based on $i_{d r}$ (Figure 4 ).

$u_{q r}^{*}$ is obtained from the closed-loop of rotor current in $q$ axial from Figure 5, which can be expressed as

$$
u_{q r}=R_{r} i_{q r}+\left(L_{r}-\frac{L_{m}^{2}}{L_{s}}\right) \frac{\mathrm{d} i_{q r}}{\mathrm{~d} t}+\left(L_{r}-\frac{L_{m}^{2}}{L_{s}}\right) \omega_{s} i_{d r}+\frac{L_{m} \psi_{s}}{L_{s}} \omega_{s} .
$$




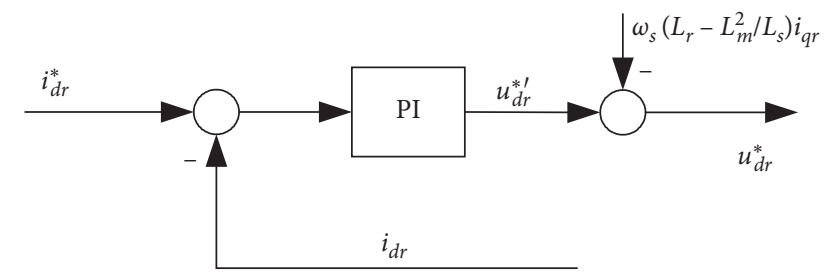

FIGURE 4: Closed-loop control of rotor current in $d$ axis.

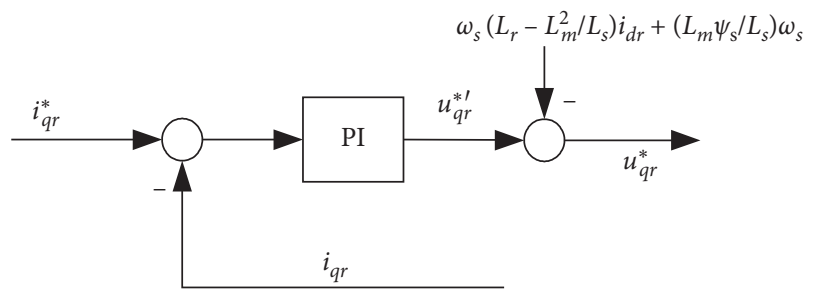

Figure 5: Closed-loop control of rotor current in $q$ axis.

According to the characteristics of the reactive power on the stator side, the total copper consumption of the system is minimized in the generating process of the DFIM. The copper loss equation of the DFIM is

$$
P_{C u}=\left(i_{q s}^{2}+i_{d s}^{2}\right) R_{s}+\left(i_{q r}^{2}+i_{d r}^{2}\right) R_{r} .
$$

Transforming equation (13) into a function of stator current in $d$-axis,

$$
\begin{aligned}
P_{C u}= & f\left(i_{d s}\right)=\left(R_{s}+\frac{L_{s}^{2}}{L_{m}^{2}} R_{r}\right) i_{d s}^{2}-\frac{\psi_{d s} L_{s} R_{r}}{L_{m}^{2}} i_{d s} \\
& +\frac{\psi_{d s}^{2}}{L_{m}^{2}} R_{r}+\left(R_{s}+\frac{L_{s}^{2}}{L_{m}^{2}} R_{r}\right) i_{q s}^{2} .
\end{aligned}
$$

And let

$$
\frac{\mathrm{d} P_{C u}}{\mathrm{~d} i_{d s}}=0 \Rightarrow i_{d s}=\frac{L_{s} R_{r} \psi_{d s}}{R_{s} L_{m}^{2}+R_{r} L_{s}^{2}}=\frac{\psi_{s}-L_{m} i_{d r}}{L_{s}},
$$

where

$$
Q_{s}^{*}=n_{p} \omega_{1} \frac{L_{s} R_{r} \psi_{d s}^{2}}{R_{s} L_{m}^{2}+R_{r} L_{s}^{2}} .
$$

The preset reactive power is given according to the system power factor requirements. Combining equations (14) and (15), the preset reactive current can be calculated. Stator flux linkage is the key to rotation transformation in vector control technology. In the static coordinate system, the stator voltage equation ignoring the stator resistance is given as

$$
\left\{\begin{array}{l}
u_{\alpha}=\frac{\mathrm{d} \psi_{\alpha}}{\mathrm{d} t}, \\
u_{\beta}=\frac{\mathrm{d} \psi_{\beta}}{\mathrm{d} t} .
\end{array}\right.
$$

As can be seen from the voltage equation in the static coordinate system, the stator voltage synthesis vector is $90^{\circ}$ ahead of the stator flux vector. The observed three-phase voltage of stator is transformed by $3 / 2$, and the stator voltages $u_{\alpha}, u_{\beta}$ of the stationary coordinate system are obtained. Then let $\theta$ be the stator voltage vector position, and stator flux vector position can be expressed as $\theta_{1}=\theta-90^{\circ}$ to locate the position of the $d$ axis of the coordinate system. The rotor position $\theta_{r}$ can be measured directly through the code disc. The position of $d$ axis refers to the rotor position being $\theta_{s}=\theta_{1}-\theta_{r}$. Assuming that the rotor voltage in $d-q$ axis is given, the three-phase voltage on the rotor side $u_{a r}^{*}, u_{b r}^{*}, u_{c r}^{*}$ can be obtained through rotation transformation and $2 / 3$ transformation (see Figure 6). The power control scheme can thus be summarized as shown in Figure 3, from which the decoupling control of the active and reactive power of the variable-speed and constant frequency DFIM system is realized.

\section{Control of VS-PSU for Regulating Wind Power Fluctuations}

3.1. VS-PSU for Stable Wind Power Generation. The great fluctuation exists in wind power since the output of the wind turbine changes with the variation of the wind speed. In a short time-scale, the wind power cannot be kept steady by the wind turbine generator due to its small inertia. The fast fluctuation of wind power will inevitably affect the power flow, voltage, and frequency of the regional power grid. Typical characteristics of randomness and unpredictability of wind power plants are recorded in Figure 7. As can be seen in Figure 8, the active power of VS-PSU increases nonlinearly with the increase of wind power, which indicates that the fluctuation of wind speed will lead to the frequent fluctuation of active power at low wind speed and cause the frequent change of network power flow eventually. Meanwhile, the VS-PSU will not be connected to the grid for power generation when the wind speed is too high (safe consideration) or too low.

3.2. Wind Turbine Model. The relationship between the mechanical energy, $\mathrm{Pw}$, output by the wind turbine, and the wind speed, $V w$, corresponding to the captured wind energy is presented in the following:

$$
P_{w}=\frac{1}{2} \rho A V_{w}^{3} \cdot C_{p}(\lambda, B)
$$

in which the power coefficient $C_{p}$ is the function of tip speed ratio $\omega_{s}$ and pitch angle $s \omega_{s}=\omega_{s}-\omega_{r}$ :

$$
\begin{aligned}
C_{p}(\lambda, B) & =0.22\left(\frac{116}{\lambda^{\prime}}-0.4 \beta-5.0\right) e^{\left(-(12.5) / \lambda^{\prime}\right)}, \\
\frac{1}{\lambda^{\prime}} & =\frac{1}{\lambda+0.08 \beta}-\frac{0.035}{\beta^{3}+1} .
\end{aligned}
$$

The mechanical torque output of the wind turbine $T_{w}$ can be expressed as

$$
T_{w}=\frac{P_{w}}{\omega_{w}}=\frac{P_{w}}{\omega_{m} / G} .
$$




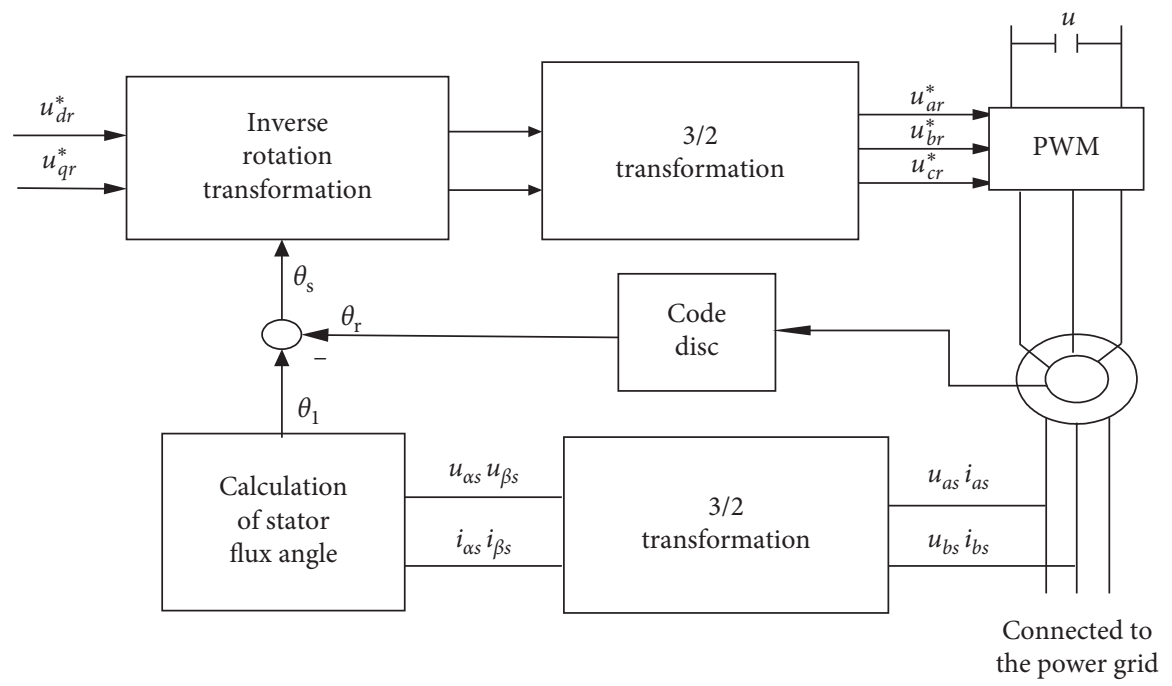

FIGURE 6: Stator flux and rotor three-phase voltage calculation.

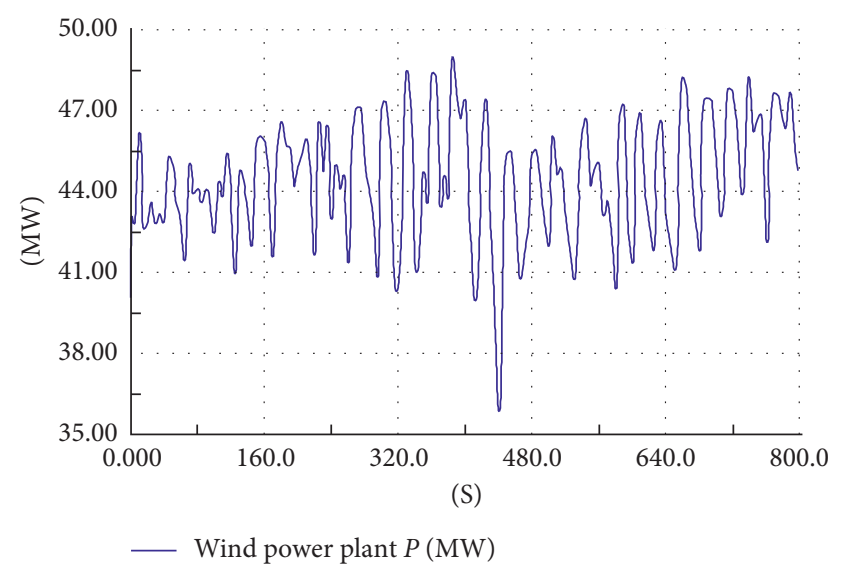

Figure 7: Characteristics of the wind power.

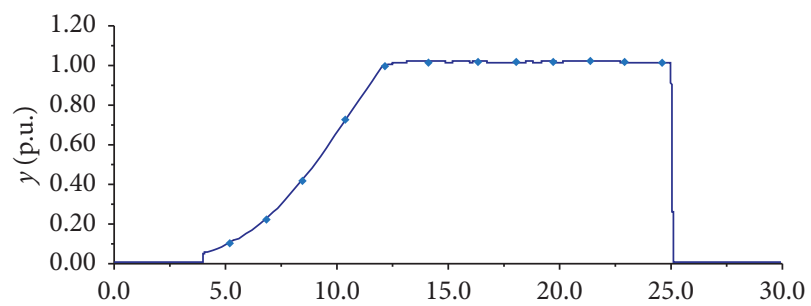

FIgURE 8: Relationship between wind power of VS-PSU and wind speed.

Maximum mechanical power can be obtained by adjusting the pitch angle of a wind turbine according to the alternation of wind speed. $C_{p}$ and $P_{w}$ characteristic curve of a wind turbine is shown in Figures 9 and 10, respectively. It can be seen from Figure 9 that there is only one value of $\psi_{s}$ that enables $C_{p}$ to achieve its maximum when the pitch angle is fixed, and the corresponding tip velocity ratio is called the optimal tip velocity ratio of wind turbines.

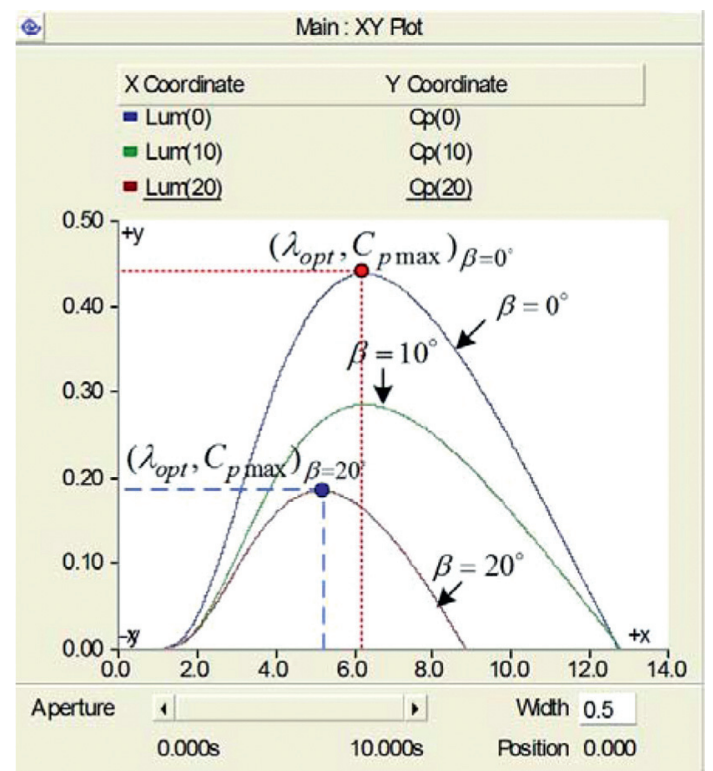

Figure 9: Mechanical power characteristic of the wind turbine.

3.3. Control of VS-PSU Integrated System. The idea of using VS-PSU to control the fluctuation of output of wind power plant is similar to the function of the low-pass filter. Therefore, the low-pass filter can be used to filter out the low-frequency components, and then the medium-frequency and high-frequency signals of wind power regulation needed by the VS-PSU can be obtained. This section is dedicated to present the operation characteristics of the above proposed control strategy based on the DIgSILENT, and the corresponding schematic diagram is provided in Figure 11. The simulation model equipped with a set of $300 \mathrm{MW}$ VS-PSU connected to the local power grid in the region with high permeability of new energy is designed and connected to the $220 \mathrm{kV}$ ac power grid through the step-up transformer. As shown in Figure 12, two control schemes of the VS-PSU integrated with wind power are proposed 


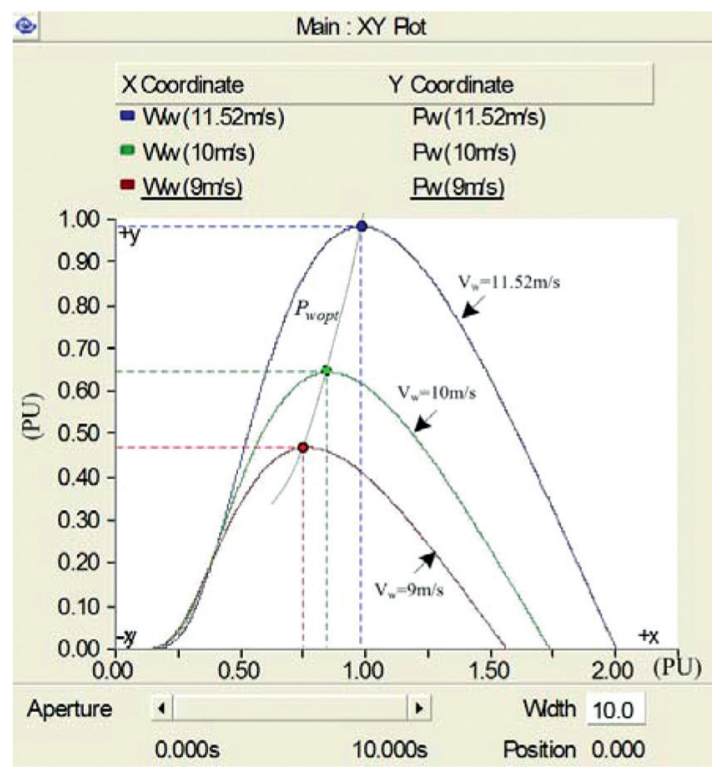

Figure 10: Mechanical energy characteristic of the wind turbine.

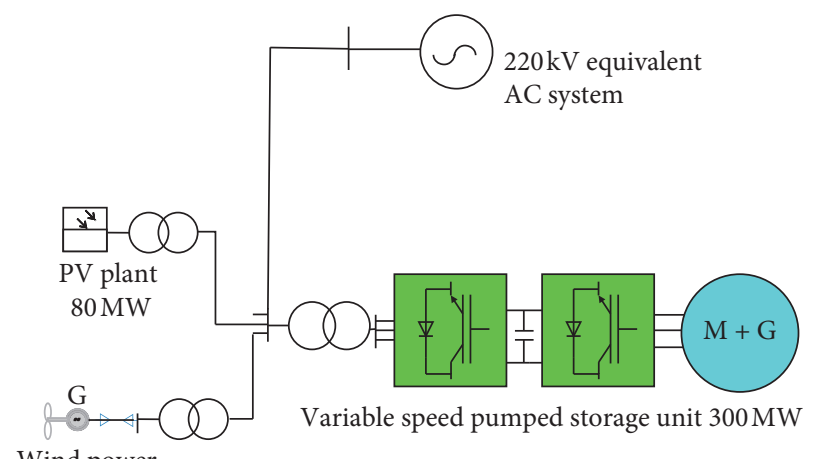

Wind power plant $200 \mathrm{MW}$

FIGURE 11: Systematic diagram of the power system integrated with VS-PSU in which a $200 \mathrm{MW}$ wind power and a $80 \mathrm{MW}$ photovoltaic power station are connected to the bus (here we focused only on the integrated operation characteristics of the wind power).

according to different input signals. The input signal of realtime or forecasted power is superimposed on the reference power through the restrain fluctuate module. In scheme one, the real-time power output of the wind power plant is considered as an input signal (see Figure 13), $P_{\text {in }}$. Figure 14 shows the active power output of wind turbines obtained from numerical simulation based on different low-pass filtering time constants $(T 1=5 \mathrm{~s}, T 2=10 \mathrm{~s}, T 3=15 \mathrm{~s})$. Results show that the variation range of the active power output and frequency of the wind turbine in the near region have been effectively reduced, which relieves partial pressure in the power regulation by the conventional unit. Besides, regulating the speed of VS-PSU is faster with increase in low-pass filtering time constants. On the other hand, the output waveform of the controller is delayed compared with the input waveform due to the lag effect of the low-pass filter,

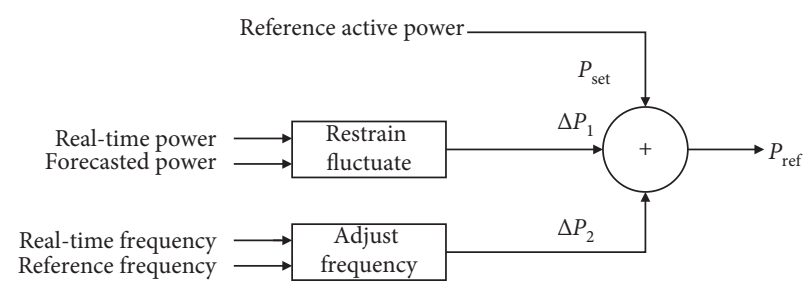

FIGURE 12: Control schemes of the VS-PSU integrated with wind power adopting different input signals (real-time power and forecasted power).

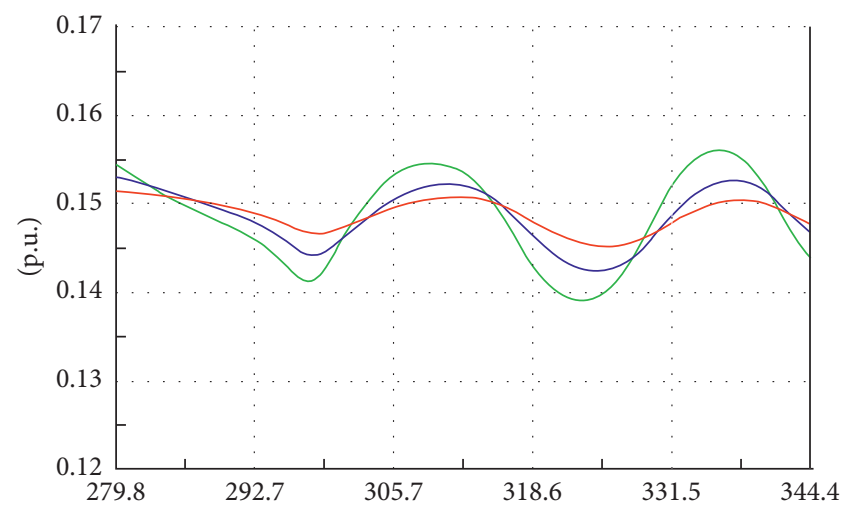

(S)

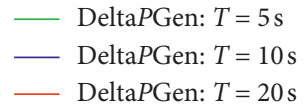

Figure 13: Active power command of the VS-PSU.

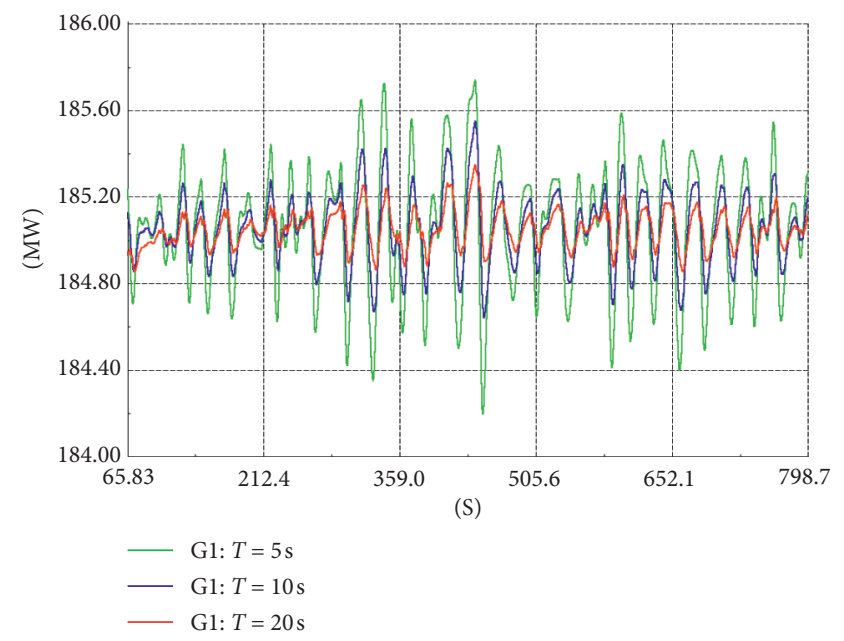

FIGURE 14: Power output of the VS-PSU in the near region.

which is not conducive to power system dispatching. The wind power plants are generally equipped with wind power prediction system, which can forecast wind power in advance. Therefore, scheme two adopts the method based on the predicted wind power data of the power plants as the input signal, $P_{\text {in }}$. Two control schemes are compared in Figure 15 and the negative power output is obtained 


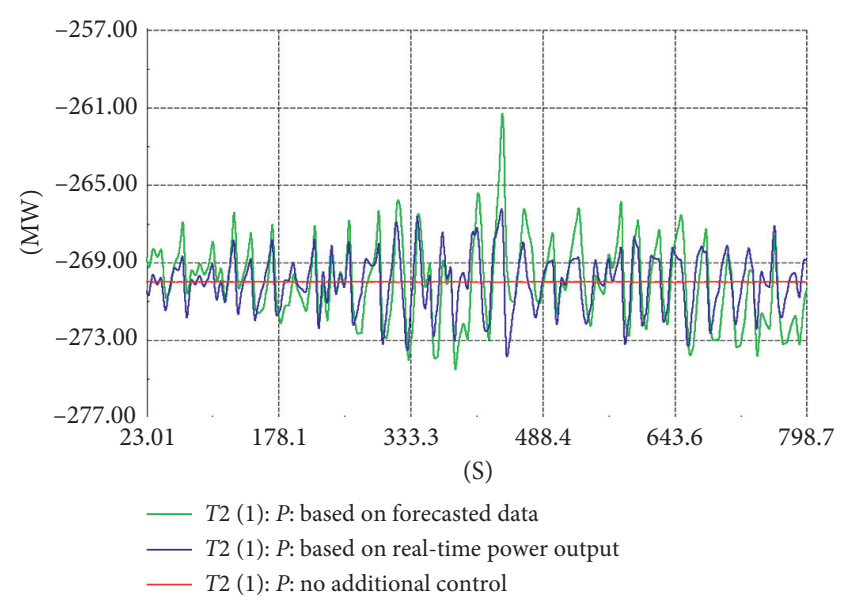

FIgURE 15: Power output comparisons among scheme one (blue), scheme two (green), and no additional control (red).

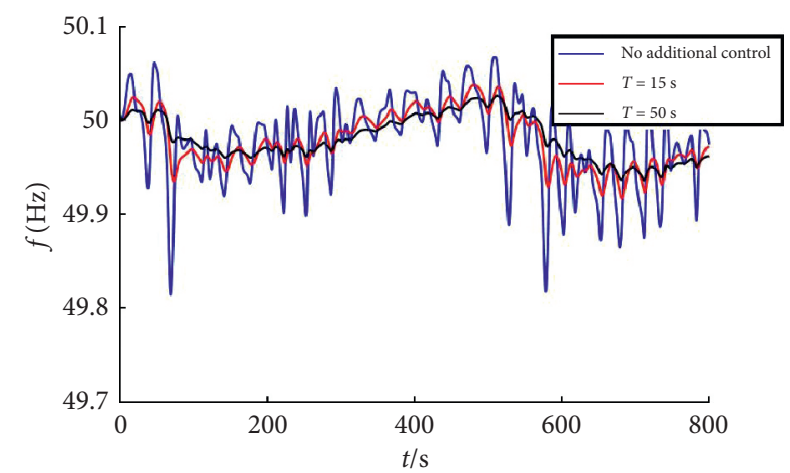

FIGURE 16: Frequency responses of the VS-PSU integrated wind power generation system.

from the perspective of grid side under pumping mode. The power output of the VS-PSU without integration of the wind power is constant (red one) as labeled with no additional control. It can be concluded that the fluctuation of wind power can be effectively suppressed based on the VS-PSU with both the schemes proposed in this study. However, the "delay" effect of the low-pass filter has been effectively compensated based on the predicted power data in the second scheme. It indicates the better effect of scheme two in stabilizing the power output fluctuation of wind energy integration when compared with scheme one. Based on the wind power curve in Figure 7, the frequency responses of the VS-PSU integrated wind power generation system under different filtering time constants (no additional control, $T=15 \mathrm{~s}, T=50 \mathrm{~s}$ ) are given in Figure 16. The system frequency fluctuation is obviously reduced after the VS-PSU is adopted, and the frequency fluctuation of the system decreased significantly in the case of $T=50 \mathrm{~s}$.

\section{Conclusions}

In the present research, the control over the VS-PSU integrated wind power generation system is analyzed primarily using the dq-axis vector control strategy. The operation characteristics of wind power after the integration of VSPSU is simulated based on DIgSILENT platform considering different filtering time. Results show that the VS-PSU can effectively reduce the regulation pressure of the conventional power unit, especially when taking the predicted power data of the wind power plant as the input signal because of the delay effect of real-time power output. Additionally, the frequency fluctuation of the wind power generation system is obviously reduced after the VS-PSU is adopted, and the frequency stabilization effect is better with the increase of the filter time constant. The coordinated operation of VS-PSU in wind power grid provides more safe and effective regulation approaches for the peak regulation and frequency modulation.

\section{Nomenclature}

$i_{d r}:$ Reactive current

$i_{q r}$ : Measured current

$u_{d r}^{*}$ : Rotor voltage in $d$ axial

$P_{w}$ : Mechanical energy captured by wind turbines

$\rho: \quad$ Air density

$\lambda$ : Tip velocity ratio of wind turbine

$\beta$ : $\quad$ Pitch angle

$A$ : Area swept by the impeller of a wind turbine

$V_{w}:$ Wind speed

$C_{p}$ : Conversion factor of the wind turbine

$T_{w}$ : Output of wind turbine torque

$\omega_{w}$ : Mechanical speed of a wind turbine

$\omega_{m}$ : Mechanical angular velocity of a motor

$G$ : Gear ratio.

\section{Data Availability}

The data used to support the findings of this study are available from the corresponding author upon request.

\section{Conflicts of Interest}

The authors declare no conflicts of interest.

\section{Acknowledgments}

This work was supported by the State Grid Science and Technology Project (Project no. 521104180013, "Research and Application of Key Technologies for Large Variable Speed Pumped Storages Units").

\section{References}

[1] Z. Zhou, S. Jianqiang, and W. Xuerong, "Research on the measures for safe operation of nuclear power plant," Chinese Journal of Nuclear Science and Engineering, vol. 21, no. 1, pp. 15-20, 2001.

[2] W. Awickhorst, "Management of radioactive wastes from the operation of nuclear power plants," Nuclear Engineering and Design, vol. 176, no. 1-2, pp. 171-176, 1997.

[3] M. Hu and N. Li, "Stability constrained incentive design for distributed frequency control of power grid," in Proceedings of 
the 53rd IEEE Conference on Decision and Control, pp. 2487-2492, Los Angeles, CA, USA, December 2014.

[4] S. Padrón, J. F. Medina, and A. Rodríguez, "Analysis of a pumped storage system to increase the penetration level of renewable energy in isolated power systems. Gran Canaria: a case study," Energy, vol. 36, no. 12, pp. 6753-6762, 2011.

[5] S. Rehman, L. M. Al-Hadhrami, and M. M. Alam, "Pumped hydro energy storage system: a technological review," Renewable and Sustainable Energy Reviews, vol. 44, pp. 586-598, 2015.

[6] B. Steffen, "Prospects for pumped-hydro storage in Germany," Energy Policy, vol. 45, pp. 420-429, 2012.

[7] N. Sivakumar, D. Das, N. P. Padhy, A. R. Senthil Kumar, and N. Bisoyi, "Status of pumped hydro-storage schemes and its future in India," Renewable and Sustainable Energy Reviews, vol. 19, pp. 208-213, 2013.

[8] J. I. Pérez-Díaz, M. Chazarra, J. García-González, G. Cavazzini, and A. Stoppato, "Trends and challenges in the operation of pumped-storage hydropower plants," Renewable and Sustainable Energy Reviews, vol. 44, pp. 767-784, 2015.

[9] C. Dong, Y. Qi, W. Dong, X. Lu, T. Liu, and S. Qian, "Decomposing driving factors for wind curtailment under economic new normal in China," Applied Energy, vol. 217, pp. 178-188, 2018.

[10] J.-K. Lung, Y. Lu, W.-L. Hung, and W.-S. Kao, "Modeling and dynamic simulations of doubly fed adjustable-speed pumped storage units," IEEE Transactions on Energy Conversion, vol. 22, no. 2, pp. 250-258, 2007.

[11] O. Alizadehmousavi and M. Nick, "Stochastic security constrained unit commitment with variable-speed pumpedstorage hydropower plants," in Proceedings of the 2016 Power Systems Computation Conference (PSCC), June 2016.

[12] T. Kuwabara, A. Shibuya, H. Furuta, E. Kita, and K. Mitsuhashi, "Design and dynamic response characteristics of $400 \mathrm{MW}$ adjustable speed pumped storage unit for Ohkawachi power station," IEEE Transactions on Energy Conversion, vol. 11, no. 2, pp. 376-384, 1996.

[13] V. Mostafa and N. Arne, "Variable-speed operation of hydropower plants: past, present, and future," in Proceedings of the 2016 XXII International Conference on Electrical Machines (ICEM), pp. 640-646, Lausanne, Switzerland, September 2016.

[14] T. Shiozaki, T. Suzumura, T. Watanabe, and T. E. P. Co, "Design and manufacturing of the world's largest $475 \mathrm{MVA} /$ $460 \mathrm{MW}$ adjustable speed generator-motor for pumped storage hydro electric power plant," CIGRE, 2014.

[15] T. A. Taguchi, K. Mukai, K. Yanagisawa et al., "Variable speed pumped storage system fed by large-scale cycloconverter," in Proceedings of the 4th European Conference on Power Electronics and Applications, vol. 2, Institution of Electrical Engineers, European Power Electronics Association, Florence, Italy, pp. 237-324, September 1991.

[16] A. Bocquel and J. Janning, "Analysis of a $300 \mathrm{MW}$ variable speed drive for pump-storage plant applications," in Proceedings of the 2005 European Conference on Power Electronics and Applications, pp. 12-14, Dresden, Germany, September 2005.

[17] Z. Ming, Z. Kun, and L. Daoxin, "Overall review of pumpedhydro energy storage in China: status quo, operation mechanism and policy barriers," Renewable and Sustainable Energy Reviews, vol. 17, pp. 35-43, 2013.

[18] L. Belhadji, S. Bacha, I. Munteanu, A. Rumeau, and D. Roye, "Adaptive MPPT applied to variable-speed microhydropower plant," IEEE Transactions on Energy Conversion, vol. 28, no. 1, pp. 34-43, 2013.

[19] N. Li and K. W. Hedman, "Evaluation of the adjustable-speed pumped hydro storage in systems with renewable resources," in Proceedings of the 2016 IEEE/PES Transmission and Distribution Conference and Exposition (T\&D), IEEE, Dallas, TX, USA, May 2016.

[20] N. Sivakumar, D. Das, and N. P. Padhy, "Variable speed operation of reversible pump-turbines at Kadamparai pumped storage plant-a case study," Energy Conversion and Management, vol. 78, pp. 96-104, 2014.

[21] J. Janning and A. Schwery, "Next generation variable speed pump-storage power stations," in Proceedings of the 2009 13th European Conference on Power Electronics and Applications, pp. 5559-5568, IEEE, Barcelona, Spain, September 2009.

[22] B. G. Teshager, M. Han, Z. Meng, X. Song, J. Xu, and P. Simiyu, "Phasor model simulation of a grid integrated variable speed pumped storage system," The Journal of Engineering, vol. 2017, no. 13, pp. 1002-1009, 2017.

[23] M. Fujimitsu, T. Komatsu, K. Koyanagi, K. Hu, and R. Yokoyama, "Modeling of doubly-fed adjustable-speed machine for analytical studies on long-term dynamics of power system," in Proceedings of the International Conference on Power System Technology, pp. 25-30, IEEE, Perth, WA, Australia, December 2000.

[24] Y. Pannatier, B. Kawkabani, J.-J. C. Nicolet, A. Simond, A. Schwery, and P. Allenbach, "Investigation of control strategies for variable-speed pump-turbine units by using a simplified model of the converters," IEEE Transactions on Industrial Electronics, vol. 57, no. 9, pp. 3039-3049, 2010.

[25] J. R. Lima, G. Damm, A. Benchaib, E. Nobile, and A. Schwery, "Nonlinear control of a fully-fed variable speed pumped storage plant," IFAC-PapersOnLine, vol. 50, no. 1, pp. 32503255, 2017.

[26] A. C. Padoan, B. Kawkabani, A. Schwery et al., "Dynamical behavior comparison between variable speed and synchronous machines with PSS," IEEE Transactions on Power Systems, vol. 25, no. 3, pp. 1555-1565, 2010.

[27] A. Vargas-Serrano, A. Hamann, S. Hedtke, C. M. Franck, and G. Hug, "Economic benefit analysis of retrofitting a fixedspeed pumped storage hydropower plant with an adjustablespeed machine," in 2017 IEEE Manchester PowerTech, pp. 1-6, IEEE, Manchester, UK, June 2017.

[28] J. M. Filipe, C. L. Moreira, R. J. Bessa, and B. A. Silva, "Optimization of the variable speed pump storage participation in frequency restoration reserve market," in Proceedings of the 2016 13th International Conference on the European Energy Market (EEM), pp. 1-6, IEEE, Porto, Portugal, June 2016 . 